\title{
Two non-cytotoxic type 2 ribosome-inactivating proteins (Sambucus Sieboldiana lectin and Sambucus Nigra lectin) lead neurosphere cells to caspase-independent apoptosis.
}

\author{
Masaharu Kotani $^{*}$, Yasunori Sato $^{2}$, Akemichi Ueno ${ }^{3}$, Rina Shibuya ${ }^{1}$, Toshinori Ito ${ }^{4}$, Masato Imada ${ }^{5}$, \\ Kouichi Itoh 6 \\ ${ }^{1}$ Department of Molecular and Cellular Biology, Faculty of Pharmaceutical Sciences, Ohu University, Fukusima, Japan \\ ${ }^{2}$ Department of Biological Environment Health, Faculty of Pharmaceutical Sciences, Hokuriku University, Kanazawa, \\ Japan \\ ${ }^{3}$ Department of Health Chemistry, Faculty of Pharmaceutical Sciences, Ohu University, Fukusima, Japan \\ ${ }^{4}$ Department of English Language Education, Faculty of Pharmaceutical Sciences, Ohu University, Fukusima, Japan \\ ${ }^{5}$ Department of Functional Morphology, Nihon University School of Medicine, Tokyo, Japan \\ ${ }^{6}$ Laboratory for Pharmacotherapy and Experimental Neurology, Kagawa School of Pharmaceutical Sciences, \\ Tokushima Bunri University, Kagawa, Japan
}

\begin{abstract}
We found a new phenomenon of cell damage and/or cell death of almost all types of neurosphere cells derived from telencephalons of mouse embryos. The cell damage/death was induced by non-cytotoxic type 2 ribosome-inactivating proteins: Sambucus Sieboldiana lectin (SSA) and Sambucus Nigra lectin (SNA). Self-renewal and aggregation of the neurosphere cells were inhibited under the presence of SSA or SNA. These lectins led the neurosphere cells to cell damage by making them lose their proliferation capacity. It was found that Sia $\alpha 2-6 \mathrm{Gal} \beta 1$-4GlcNAc or Sia $\alpha 2-6 \mathrm{Gal}$ on the membrane of neurosphere cells play an important role in the induction of cell damage of neurosphere cells. Moreover, despite the fact that most of the neurosphere cells cultured under the presence of SSA or SNA were Annexin V positive, these cells were not identified by DNA ladder assays. Additionally, the cells were not rescued from cell death even under the presence of a pan-caspase inhibitor. These findings imply that cell death of neurosphere cells caused by SSA or SNA is caspase-independent apoptosis via an exogenous pathway. SSA and SNA recognition molecules were detected as 39 and $42 \mathrm{kDa}$ glycoproteins on the membrane of neurosphere cells.
\end{abstract}

Keywords: Apoptosis, Cell damage, Lectin, Mouse, Neurospheres.

Accepted on February 07, 2018

\section{Introduction}

Neurospheres are spherical cellular aggregates which consist of undifferentiated neural cells such as neural stem cells (NSCs), neural progenitor cells and neuroblast cells, and which can be obtained by floating culture [1]. In this paper, undifferentiated neural cells in neurospheres are collectively referred to as neurosphere cells. They have been used in a wide range of studies, such as neural stem cell (NSC) identification and isolation, proliferation and maintenance of NSCs, and differentiation of NSCs into neuronal and glial cells [2-7].

On the other hand, mechanisms involved in the formation of neurospheres are not fully understood. More especially, molecules that induce cell aggregation in neurosphere formation are not fully determined. We previously found that neurospheres can easily be dispersed into single cell suspension by means of mechanical pipetting [8]. This characteristic suggested that cell aggregation in the formation of neurospheres may be driven by a weak binding, such as a bind between sugar chains. On this hypothesis, we have been using lectins as detection probes in the exploration for molecules that induce cell-aggregation because they bind to sugar chains.

During the exploration, we found an unexpected phenomenon: neither proliferation of neurosphere cells nor formation of neurospheres was observed under the presence of two types of lectins, Sambucus Sieboldiana lectin (SSA) and Sambucus Nigra lectin (SNA). SSA was isolated from Japanese 
elderberry bark, and SNA from elderberry bark $[9,10]$. They are classified as non-cytotoxic type 2 ribosome-inactivating proteins that do not have biological activities such as mitogenicity or cytotoxicity [11]. There have been no reports that SSA or SNA has cytotoxicity against mammalian cells, including neurosphere cells. The phenomenon mentioned above offered us the possibility that SSA and SNA might have a cell-damaging effect on neurosphere cells via an exogenous pathway because mitogenicity and cytotoxicity of lectins are generally activated by the bind to sugar chains of glycoproteins or glycolipids expressed on the membrane of living mammalian cells [12-15].

In this study, we show that SSA and SNA lead neurosphere cells to caspase-independent apoptosis via an exogenous pathway. We also discuss possible glycoprotein molecules on neurosphere cells that are recognized by SSA and SNA.

\section{Materials and Methods}

\section{Cells and cell cultures}

Neurospheres derived from telencephalons in ICR mice of embryonic day 14.5 (E14.5) were prepared by the following method: The tissues were taken as single cell suspension by trypsin-EDTA treatment and pipetting. These cells were cultured in neurosphere culture medium (NCM), which was made by adding $20 \mathrm{nM}$ epidermal growth factor (EGF; ProSpec-Tany TechnoGene, Rehovot, ISRAER), $20 \mathrm{nM}$ basicfibroblast growth factor (b-FGF; PEPROTECH, NJ, USA), 20 nM leukemia inhibitory factor (LIF; Wako, Tokyo, Japan) and $5 \mathrm{ml}$ of B27 supplement without vitamin A (Invitrogen, CA, USA) to $500 \mathrm{ml}$ of neurosphere basic medium, which consisted of $30 \mathrm{nM}$ sodium selenite, $60 \mu \mathrm{M}$ putrescine, $20 \mathrm{nM}$ progesterone, transferrin $(50 \mathrm{mg})$, insulin $(12 \mathrm{mg})$, sodium bicarbonate $(0.126 \mathrm{~g})$, D-glucose $(3.0 \mathrm{~g}), 1 \mathrm{M}$ HEPES $(2.5 \mathrm{ml})$, $200 \mathrm{mM}$ glutamine $(5.0 \mathrm{ml})$ and $492.5 \mathrm{ml}$ of F12/D-MEM (1:1) medium (Invitrogen). Subculture of neurospheres was performed as follows: Neurospheres were dispersed into single neurosphere cells by mechanical pipetting, and then, the neurosphere cells were spread onto new dishes with NCM. Jurkat cells, an immortalized line of human T lymphocyte cells that were derived from the peripheral blood of a patient with acute lymphoblastic leukemia, were cultured in the RPMI-1640 (Invitrogen) containing 10\% fetal calf serum (FCS), $2 \mathrm{mM} \mathrm{1-}$ glutamine, $1 \mathrm{mM}$ sodium pyruvate, $100 \mathrm{nM}$ non-essential amino acids and $10 \mathrm{mM}$ HEPES. All the experiments with animals were performed according to the guidelines of Ohu University Animal Research Committee.

\section{Lectins and antibody}

Sugar chain binding specificity of the lectins used in this study is summarized in Table 1. Erythrina cristagalli (ECA), Lotus tetragonolobus (Lotus), Maackia amurensis (MAM), Arachis hypogaea (PNA), SSA and Triticum vulgare (WGA) were purchased from J-OIL MILLS (Tokyo, Japan). Fluorescein isothiocyanate (FITC) conjugated SSA (FITC-SSA), biotinylated SSA (bio-SSA), FITC-MAM and bio-MAM were also purchased from J-OIL MILLS. SNA, FITC-SNA and bioSNA were purchased from Vector Laboratory (CA, USA). FITC-lectins were adjusted to the concentration of $100 \mu \mathrm{g} / \mathrm{ml}$ and stored at $4^{\circ} \mathrm{C}$ until before use, and all the other lectins were adjusted to the concentration of $1 \mathrm{mg} / \mathrm{ml}$, and stored at $-30^{\circ} \mathrm{C}$ until just before use. We used purified INCA monoclonal antibody (mAb) $(1 \mathrm{mg} / \mathrm{ml}$, rat $\mathrm{IgG} 2 \mathrm{a}$ isotype), which reacts to $O$-linked sugar chain portions of glycoproteins expressed on the membrane surface of neuroepithelial and ependymal cells in mouse brains [16].

Table 1. Binding specificity of lectins.

\begin{tabular}{lll}
\hline Lectins & Sugar chains & Sugar chain type \\
\hline Lotus & L-Fucose & O-linked \\
\hline WGA & (GlcNAc) $n$ & $N$-linked \\
\hline PNA & Galß1-3GalNAc & O-linked \\
\hline ECA & Galß1-4GlcNAc & N/O-linked \\
\hline MAM & Siaq-3Galß1-4GIcNAc & N-linked \\
\hline SNA & Siaa2-6Gal/Siaa2-3Gal & $N$-linked \\
\hline SSA & Siaa2-6Galß1-4GlcNAc & $N / O$-linked \\
\hline
\end{tabular}

Gal, galactose; GalNAc, N-Acetyle-D-galactosamine; GlcNAc, N-Acetyle-Dglucosamine; Sia, Sialic acid; $N, N$-linked sugar chain; $O$, O-linked sugar chain.

\section{Neurosphere formation assays}

Neurosphere cells were separated into single cell suspension by mechanically pipetting neurospheres and were spread into each well of 96-well flat bottom plates on the condition of $1 \times 10^{4}$ living cells $/ 100 \mu \mathrm{l} \mathrm{NCM} /$ well, and $1 \mu \mathrm{l}$ of lectin $(1 \mathrm{mg} / \mathrm{ml})$ or 1 $\mu \mathrm{l}$ of INCA $\mathrm{mAb}(1 \mathrm{mg} / \mathrm{ml})$ was immediately added and the samples were cultured at $37^{\circ} \mathrm{C}$ for $4 \mathrm{~d}$. The degree of neurosphere formation was observed with an inverted phasecontrast microscope.

\section{Clonal expansion and cell aggregation assays of neurosphere cells}

A clonal expansion assay with neurosphere cells was performed as follows: Neurosphere cells were spread into each well of 96-well flat bottom plates on the condition of 1 living cell $/ 200 \mu \mathrm{l} \mathrm{NCM} /$ well, and $2 \mu \mathrm{l}$ of lectin $(1 \mathrm{mg} / \mathrm{ml})$ or $2 \mu \mathrm{l}$ of phosphate-buffered saline (PBS) were immediately added and they were cultured at $37^{\circ} \mathrm{C}$ for $8 \mathrm{~d}$. Half of the medium was changed on day 4 on the condition as mentioned. The number of neurospheres formed was counted under an inverted phasecontrast microscope on day 8 .

A cell aggregation assay with neurosphere cells was performed as follows: Neurosphere cells were spread into each well of 96well flat bottom plates on the condition of $1 \times 10^{4}$ living cells $/ 100 \mu \mathrm{NCM} /$ well, and $1 \mu \mathrm{l}$ of lectin $(1 \mathrm{mg} / \mathrm{ml})$ into one well of the same plates was immediately added and they were cultured for $4 \mathrm{~h}$ at $4^{\circ} \mathrm{C}$ or $37^{\circ} \mathrm{C}$. The degree of cell aggregation was observed under an inverted phase-contrast microscope. 


\section{Cell-proliferative and cell-damage assays}

Time-dependent cell proliferation and cell-damage assays were performed with WST-1 (Roche, Basel, Swiss) according to the manufacture's protocol. In brief, neurosphere cells were spread into each well of 96-well flat-bottom plates on the condition of $1 \times 10^{4}$ living cells $/ 100 \mu \mathrm{NMC} /$ well, and $1 \mu \mathrm{l}$ of lectin $(1$ $\mathrm{mg} / \mathrm{ml}$ ) was immediately added and they were cultured for 0,1 , 2, 3 or $4 \mathrm{~d}$. After cultivation, $10 \mu \mathrm{l}$ of WST-1 was added, followed by incubation at $37^{\circ} \mathrm{C}$ for $3 \mathrm{~h}$. The plates were measured by a microplate reader with the wavelength of 450 nm.

Dose-dependent cell proliferation and cell-damage assays were performed as follows with WST-1: Neurosphere cells were spread into each well of 96-well flat-bottom plates on the condition of $1 \times 10^{4}$ living cells/100 $\mu \mathrm{lNCM} /$ well, and $1 \mu \mathrm{l}$ of lectin of various concentrations (from $0.1 \mathrm{mg} / \mathrm{ml}$ to $2.0 \mathrm{mg} / \mathrm{ml}$ ) was immediately added and they were cultured at $37^{\circ} \mathrm{C}$ for $4 \mathrm{~d}$. After the culture, $10 \mu 1$ of WST-1 were added, followed by incubation at $37^{\circ} \mathrm{C}$ for $3 \mathrm{~h}$. The plates were measured by a microplate reader with the wavelength of $450 \mathrm{~nm}$.

\section{Detection of apoptosis cells and DNA ladder assays}

Detection of apoptosis cells was performed with Apoptotic/ Necrotic Cells Detection Kit (Promo Kine, Heidelberg, Germany) according to the manufacture's protocol. The stained cells were observed under a microscope (Axiovert $100 \mathrm{M}$; Carl Zeiss, Oberkochen, Germany) equipped with a confocal laser scanning system (LMS510; Carl Zeiss). Annexin V+ and EthD III + cells were quantified by image analysis of photographs acquired under the above-mentioned confocal laser microscopy.

A DNA ladder assay was performed with Apoptosis Ladder Detection Kit (Wako) according to the manufacture's protocol. The electrophoresis samples were prepared by adding $2 \mu 1$ of loading buffer to $10 \mu \mathrm{l}$ of DNA samples in sample wells with $1.5 \%$ agarose gel. After electrophoresis, agarose gel was stained by gentle stirring for $2 \mathrm{~h}$. The stained gel was set on a UV trans-illuminator with the wave length of $260 \mathrm{~nm}$ and the photographs were taken with a camera.

\section{Measurement of caspase activities}

Caspase activities were measured with FLICE/Caspase-3, -8 and -9 Colorimetric Assay Kits (BioVision, CA, USA) according to the manufacture's protocol. In brief, neurosphere cells were spread into each well of 6-well flat bottom plates on the condition of $1 \times 10^{6}$ living cells $/ 3 \mathrm{ml} \mathrm{NCM} /$ well and $30 \mu \mathrm{l}$ of lectin $(1 \mathrm{mg} / \mathrm{ml})$ were immediately added and they were incubated at $37^{\circ} \mathrm{C}$ for $3 \mathrm{~h}$ or $4 \mathrm{~h}$. After the incubation, they were collected into microtubes and centrifuged at 1,300 rpm for $3 \mathrm{~min}$ at $4^{\circ} \mathrm{C}$. After removing the supernatants, the cell pellets were suspended in $50 \mu \mathrm{l}$ of chilled Cell Lysis Buffer and incubated on ice for $10 \mathrm{~min}$, followed by centrifugation at $10,000 \mathrm{~g}$ for $1 \mathrm{~min}$ at $4^{\circ} \mathrm{C}$. The supernatants were transferred into new microtubes and protein concentration was measured by BCA (Thermo Scientific, IL, USA) method. On the basis of the measurements, the supernatants were diluted to $100 \mu \mathrm{g} / 50$ $\mu 1$ with Dilution buffer. $50 \mu 1$ of adjusted supernatants were put into each well of 96-well flat plates. $50 \mu \mathrm{l}$ of $2 \mathrm{X}$ Reaction Buffer (containing $10 \mathrm{mM}$ DTT) and $5 \mu \mathrm{l}$ of $4 \mathrm{mM}$ IETD-pNA substrate $(200 \mu \mathrm{M}$ final concentrations $)$ were added. The plates were incubated at $37^{\circ} \mathrm{C}$ for $2 \mathrm{~h}$ and the plates were read by a microplate reader with the wavelength of $405 \mathrm{~nm}$.

\section{Inhibition assays of caspase and other enzymes}

Caspase inhibition was performed with used Caspase-Family Inhibitor Set II (PromoKine). Inhibitors of RIPK-1, Ras farnesyltransferase, PI3K and clathrin were used Necrostatin-1 (Cayman Chemical, MI, USA), Manumycin A (Cayman Chemical), LY294002 (Promega, WI, USA) and Pitstop2 (Sigma-Aldrich, MO, USA), respectively. Neurosphere cells were spread into each well of 96 -well flat bottom plates on the condition of $1 \times 10^{4}$ living cells $/ 100 \mu \mathrm{lNCM} /$ well. Then, $1 \mu \mathrm{l}$ of lectin $(1 \mathrm{mg} / \mathrm{ml})$ and $1 \mu l$ of inhibitors of various concentrations were immediately added. The plates were cultured for $4 \mathrm{~d}$. After the culture, $10 \mu \mathrm{l}$ of WST-1/well were added, and the plates were incubated at $37^{\circ} \mathrm{C}$ for $3 \mathrm{~h}$ and the samples were read by a microplate reader set with the wavelength of $450 \mathrm{~nm}$.

\section{Western blotting}

Cell membrane fraction lysates $(10 \mu \mathrm{g} / \mathrm{lane})$ prepared according to Kotani et al., were separated by sodium dodecyl sulfate-polyacrylamide gel electrophoresis (SDS-PAGE) in $12.5 \%$ acrylamide (ATTO, Tokyo, Japan), and then electro blotted onto polyvinylidene difluoride (PVDF) membranes (Immobilon; GE Healthcare, Buckinghamshire, UK) according to Towbin et al. $[4,17]$. The PVDF membranes were blocked with 5\% skim milk in PBS followed by $1 \mathrm{~h}$ incubation with bio-SSA lectin $(1 \mu \mathrm{g} / 100 \mu \mathrm{l}$ of PBS), bio-SNA lectin $(0.7$ $\mu \mathrm{g} / 100 \mu \mathrm{l}$ of PBS) and bio-MAM lectin $(6 \mu \mathrm{g} / 100 \mu \mathrm{l}$ of PBS) with or without $100 \mathrm{mM}$ lactose. After washed with $1 \%$ skim milk in PBS containing $0.05 \%$ Tween-20 (T-PBS), the membranes were incubated with peroxidase (P.O)-streptavidin (Jackson Immuno Research, PA, USA) for $1 \mathrm{~h}$. The bands were visualized with a chemiluminescence detection system (GE Healthcare) according to the manufacture's protocol.

\section{Results}

\section{Effects of SSA and SNA on neurosphere formation}

As shown in Figure 1A, when neurosphere cells were cultured under the presence of SSA $(1 \mu \mathrm{g} / 100 \mu \mathrm{l})$, they were not able to form neurospheres, suggesting SSA was the impaired cell proliferation against neurosphere cells. SNA showed similar effects but they were weaker than those of SSA. In contrast, all the other lectins tested in this study and INCA mAb did not show such effects.

To get to the root of the impaired cell proliferation against neurosphere cells of SSA and SNA, we performed clonal expansion assays of neurosphere cells under the presence of 
SSA or SNA. As shown in Figure 1B, SSA completely inhibited neurosphere formation by clonal expansion. Similarly, SNA inhibited the formation of neurospheres. In contrast, no other lectins exhibited the inhibition effect. These results indicated that the impaired cell proliferation effect of SSA and SNA against neurosphere cells was caused by cellproliferation inhibition.
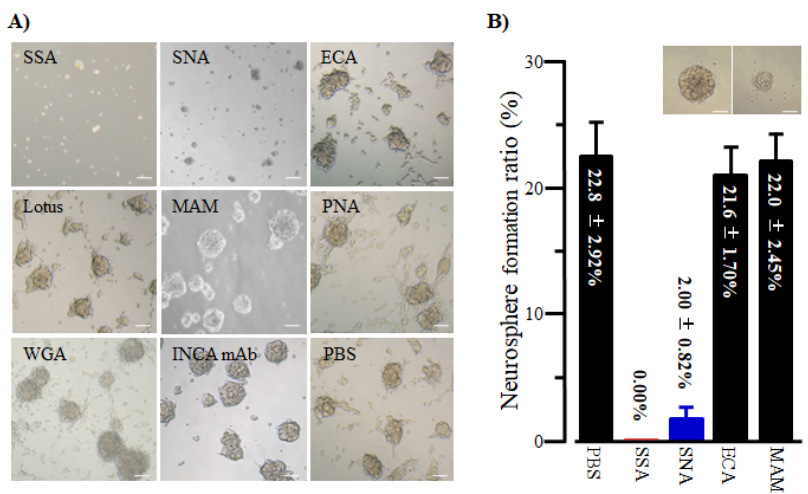

Figure 1. Proliferative inhibition of neurosphere cells by SSA and SNA. (A) Neurosphere cells were cultured in neurosphere culture medium under the presence of a lectin or INCA $m A b$ for $4 d$. Neurosphere formation was not observed under the presence of SSA or SNA. Scale bar $50 \mu \mathrm{m}$; (B) A neurosphere formation assay was performed by culturing neurosphere cells in NCM under the presence of a lectin for 8. A neurosphere was not observed under the presence of SSA and few were observed under the presence of SNA. The photographs show the typical neurospheres formed by clonal expansion of neurosphere cells for $8 d ; n=3$; Scale bar $50 \mu m$.

\section{Cell damage of neurosphere cells and Jurkat cells by SSA and SNA}

To confirm that the neurosphere cells underwent the cellproliferative inhibition by SSA and SNA, we performed cell proliferation and cell-damaging assays of neurosphere cells and Jurkat cells under the presence of SSA or SNA. Jurkat cells were used as a control [18]. As shown in Figure 2A, SSA and SNA led neurosphere cells to cell damage in a timedependent manner, although the degrees of cell damage differed between the two lectins. When neurosphere cells were cultured under the presence of SSA for $4 \mathrm{~d}$, almost all of them underwent the cell damage. The cell-damaging effect of SNA was obviously weak compared with that of SSA. On day 4, approximately 35 to $40 \%$ of the neurosphere cells were led to cell damage. However, the cell-damaging effect of SSA was far weaker on Jurkat cells than on neurosphere cells and as for SNA, the effect on Jurkat cells was scarcely observed. All the other lectins in this study never demonstrated the celldamaging effect either on neurosphere cells or Jurkat cells.

Figure 2B illustrates that SSA and SNA led neurosphere cells to cell damage in a dose-dependent manner as well. The curves considerably differed between the two lectins. When SSA was $0.5 \mu \mathrm{g} / 100 \mu \mathrm{l}$ or more, almost all the neurosphere cells were led to cell damage. On the other hand, the ratio of cell damage by SNA was approximately $40 \%$ even when SNA was 0.75 $\mu \mathrm{g} / 100 \mu \mathrm{l}$ or more.

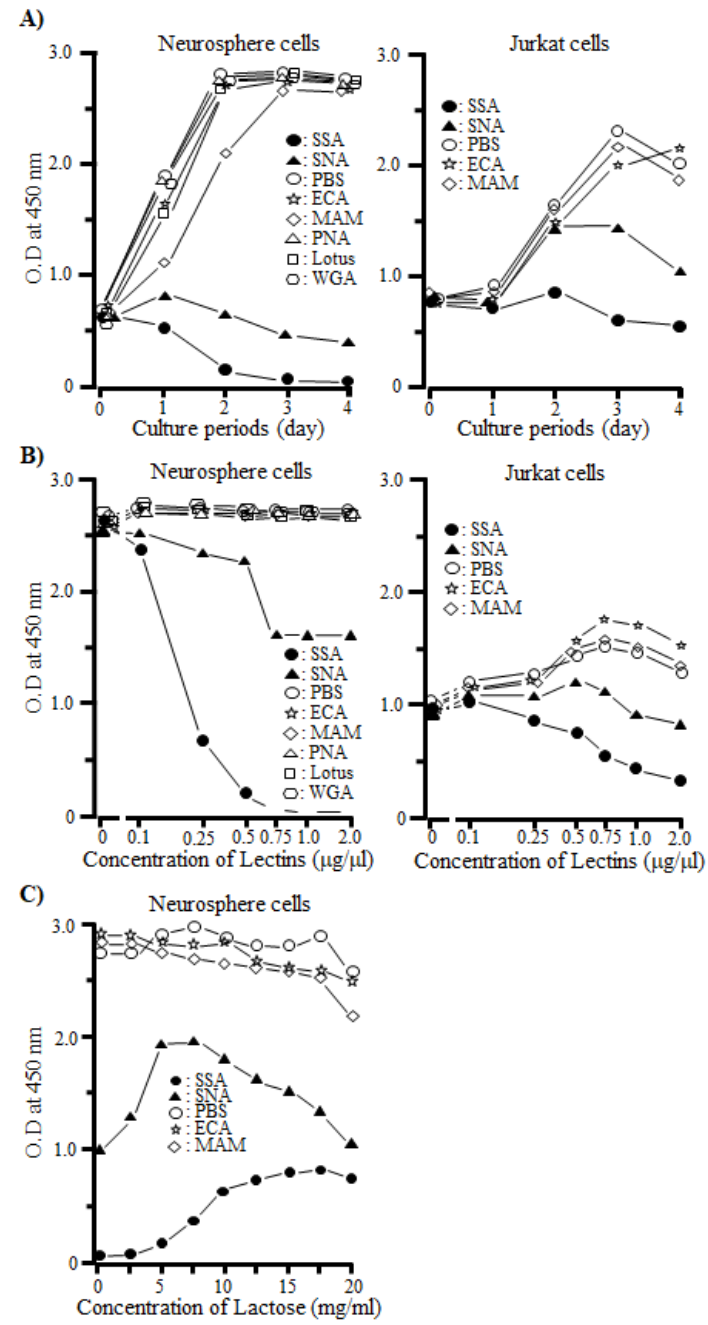

Figure 2. Cell damage of neurosphere cells and Jurkat cells by lectins. (A) Neurosphere cells were cultured in NCM under the presence of $1 \mu$ l of lectin $(1 \mathrm{mg} / \mathrm{ml})$ for $1 d, 2 d, 3 d$ and $4 d$. SSA led neurosphere cells to cell damage in a time-dependent manner. The degrees of cell damage were different between SSA and SNA. Celldamaging effect of SSA was far weaker on Jurkat cells than on neurosphere cells and the effect of SNA was scarcely observed; (B) Neurosphere cells were cultured in NCM under the presence of various concentrations of lectin for $4 d$. When $1 \mu \mathrm{g} / \mu \mathrm{l}$ of SSA was presented in NCM, almost all neurosphere cells underwent cell damage, whereas approximately 40\% of neurosphere cells underwent cell damage under the presence of SNA under the same condition as SSA. In contrast, the cell-damaging effect of SSA was far weaker on Jurkat cells and SNA had no significant effect; (C) Neurosphere cells were cultured in NCM under the presence of $1 \mu \mathrm{l}$ of lectins $(1 \mathrm{mg} / \mathrm{ml})$ and various concentrations of lactose for $4 d$. Lactose rescued neurosphere cells from cell damage by SSA/SNA in a dose-dependent manner.

Although SSA and SNA led Jurkat cells to cell damage in a dose-dependent manner as in the case of neurosphere cells, their effects were even weaker. Note that all the other lectins never caused cell damage against neurosphere cells at any dosage. 
Furthermore, we examined whether the cell-damaging effect of SSA and SNA on neurosphere cells could be inhibited by lactose, which blocks the binding between SSA or SNA and sugar chains. As shown in Figure $2 \mathrm{C}$, when the concentration of lactose was $17.5 \mathrm{mg} / \mathrm{ml}$, the cell-damaging effect of SSA was suppressed by approximately $25 \%$. In the case of SNA, at the concentration of $17.5 \mathrm{mg} / \mathrm{ml}$, lactose inhibited the celldamaging effect on neurosphere cells in a dose-dependent manner, but at any higher concentration level, inhibition did not occur. Incidentally, when the concentration of lactose was $20 \mathrm{mg} / \mathrm{ml}$, the proliferation of neurosphere cells was not observed under the presence of any lectin. This might be a result of acute change in osmotic pressure of culture condition.

These results indicated that the binding of SSA and SNA to Sia $\alpha 2-6 \mathrm{Gal} \beta 1-4 \mathrm{GlcNAc}$ and Sia 2 -6Gal expressed on the membrane of neurosphere cells was a trigger which leads neurosphere cells to cell damage.

\section{Cell biological analyses of neurosphere cells treated with SSA or SNA}

To see if the cell damage of neurosphere cells induced by SSA and SNA were apoptosis, Annexin V and EthD-III staining and DNA laddering of neurosphere cells cultured under the presence of SSA or SNA were carried out. As shown in Figure $3 \mathrm{~A}$, when neurosphere cells were cultured under the presence of SSA or SNA for $1 \mathrm{~d}$ or $2 \mathrm{~d}$, those cells were exclusively Annexin V positive (+) EthD-III negative (-), which indicate the state of early apoptosis. On day 3, Annexin V+ EthD III+ cells, the state of late apoptosis, were observed. However, the number of Annexin $\mathrm{V}+$ EthD III + neurosphere cells was significantly different between SSA and SNA. Namely, almost all (approximately 85\%) of the neurosphere cells were Annexin $\mathrm{V}+$ EthD III + when cultured with SSA, whereas smaller number (approximately 33\%) of neurosphere cells were Annexin V+ EthD III+ when cultured with SNA. In contrast, under the presence of MAM and ECN, almost all (approximately 96\%) of the neurosphere cells were Annexin VEthD III- on any given days during the experiment. However, all the DNA samples were detected not as a ladder but as a single band or smear (Figure 3B). According to these results, it is strongly suggested that the cell damage of neurosphere cells caused by SSA and SNA is apoptosis.

To clarify whether the caspase is involved in the induction of apoptosis, we measured the activity of caspase in neurosphere cells treated with SSA and SNA. The activities of caspase- 8 and 9 were weakly detected in neurosphere cells treated with SSA or SNA, but the caspase-3 was not active (Figure 3C and 3D). We used Z-VAD-FMK, a pan-caspase inhibitor, to determine whether the weak activities of caspase- 8 and 9 were involved in the induction of caspase-dependent apoptosis of neurosphere cells. As shown in Figure 4, Z-VAD-FMK was not able to rescue the neurosphere cells from apoptosis at any dosage. These results indicated that the cell death of neurosphere cells caused by SSA and SNA is caspaseindependent.
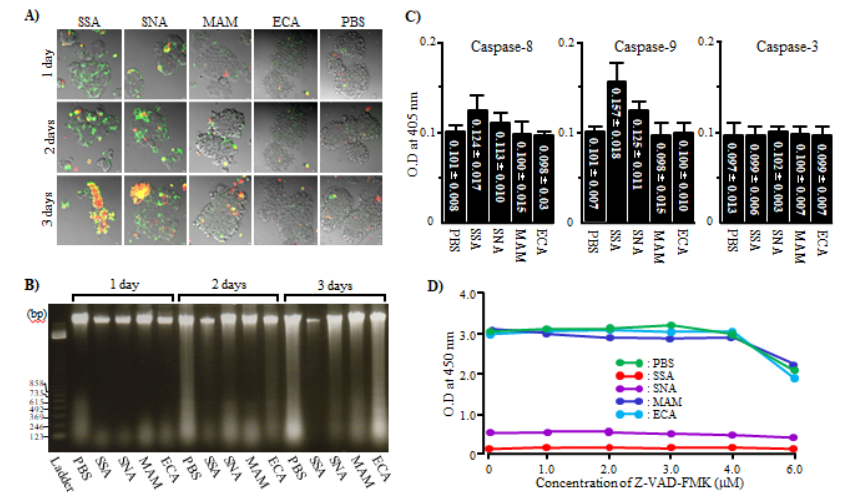

Figure 3. Cell biological analyses of neurosphere cells cultured under the presence of SSA or SNA. (A) Stainability of Annexin V: Neurosphere cells treated with lectin for $1 d, 2 d$ or $3 d$ were stained with Annexin V (green) and EthD-III (red). Scale bar $10 \mu \mathrm{m} ;(B)$ DNA laddering: DNA samples were obtained by Apoptosis Ladder Detection Kit (Wako) from the neurosphere cells treated with lectin for $1 d, 2 d$ or $3 d$. These samples were separated by 1.5\% agarose gel electrophoresis. After the electrophoresis, the gels were stained with SYBER Green I for $2 \mathrm{~h}$ in the dark and photographed. Every DNA sample exhibits a single band or smear; (C) Caspase activity: Neurosphere cells were incubated under the presence of lectin for $3 \mathrm{~h}$ or $4 \mathrm{~h}$. Activities of caspases in these cells were examined by FLICE/ Caspase-3, -8 and -9 Colorimetric Assay Kit (Bio Vision). Neurosphere cells treated with SSA or SNA showed weak activities of caspase-8 and -9, whereas the activity of caspase-3 was not detected; (D) Effect of pan-caspase inhibitor: Neurosphere cells were cultured under the presence of lectin and various concentrations of Z-VAD$F M K$ for $4 d$. Neurosphere cells were not rescued from apoptosis under the presence of a pan-caspase inhibitor.

Therefore, we examined whether the inhibition of receptorinteracting protein kinase-1 (RIPK-1), Ras or PI3K involved in the intracellular pathways of the caspase-independent apoptosis is able to rescue the neurosphere cells treated by SSA and SNA [19-21]. None of these inhibitors was able to rescue neurosphere cells from the apoptosis. Furthermore, we examined also the pathway of endocytosis by the inhibition of clathrin [22]. However, Pitstop2 was not able to rescue neurosphere cells from the apoptosis. These results suggested the presence of a novel intracellular pathway for the induction of caspase-independent apoptosis of neurosphere cells by SSA or SNA.

\section{Recognition molecules of SSA and SNA on neurosphere cells}

Finally, to identify the SSA and SNA binding molecules on the membrane of neurosphere cells, the neurosphere cell membrane lysates of neurosphere cells were applied to Western blot analyses. The results in Figure 4A indicate that the $\mathrm{N}$ linked glycoproteins recognized by SSA and SNA were those with molecular weights of $31 \mathrm{kDa}$ (gp31), $35 \mathrm{kDa}$ (gp35), 39 $\mathrm{kDa}$ (gp39), $42 \mathrm{kDa}$ (gp42) and $45 \mathrm{kDa}$ (gp45). In the Western blot analysis under the co-presence of bi-SSA or bio-SNA and lactose, the $N$-linked glycoproteins gp39 and gp42 almost lost the binding activity to SSA and SNA (Figure 5). From these results, it was suggested that SSA and SNA specifically bind to 
gp39 and gp42 molecules expressed on the membrane of neurosphere cells.
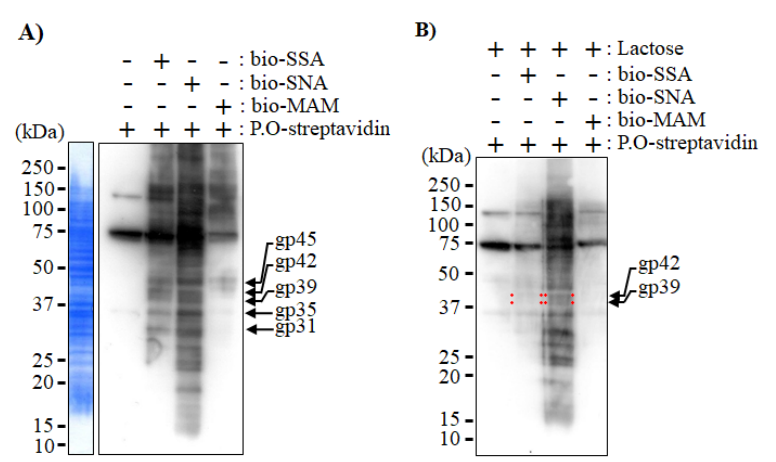

Figure 4. Western blot analysis of SSA/SNA binding molecules on the membrane surface of neurosphere cells; (A) The membrane fraction lysates prepared from neurosphere cells isolated by SDS-PAGE were electroblotted onto PVDF membranes followed by Western blotting using bio-SSA, bio-SNA or bio-MAM. The molecules recognized by SSA and SNA were $31 \mathrm{kDa}, 35 \mathrm{kDa}, 39 \mathrm{kDa}, 42 \mathrm{kDa}$ and $45 \mathrm{kDa}$. They were designated as gp31, gp35, gp39, gp42 and gp45, respectively; (B) PVDF membranes prepared under the same condition as (A) underwent Western blotting under the co-presence of bio-SSA or bio-SNA and lactose. The molecules gp39 and gp42 lost the binding activity to SSA and SNA.

\section{Discussion}

In this study, we showed that two non-cytotoxic type 2 RIPs, SSA and SNA, led neurosphere cells to cell damage and that this cell damage was caspase-independent apoptosis via an exogenous pathway. What induced the caspase-independent apoptosis might be the binding of SSA or SNA to glycoproteins expressed on the neurosphere cell membrane surface. The glycoproteins had the terminal sugar chains Sia 2 -6Gal $\beta 1-4 G l c N A c$ and/or Sia 2 -6Gal, and the triggering molecules might be gp39 and gp42. The intracellular signaling pathway involved in this apoptosis of neurosphere cells was not identified in this study.

SSA and SNA bind to the sugar chains of

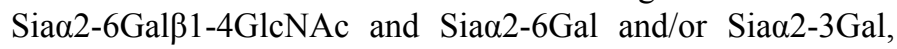
respectively (Table 1) and are classified as non-cytotoxic type 2 RIPs against animal cells [11,22]. Based on the previous reports, the result that SSA and SNA led neurosphere cells to cell damage by cell-proliferative inhibition was unexpected (Figure 1). The cell-damaging effect of SSA was strong, while that of SNA was weaker, but MAM and ECN had no such effects (Figure 2). These results indicate that SSA and SNA prevent neurosphere formation by inhibiting the proliferation of neurosphere cells and leading them to cell damage. The

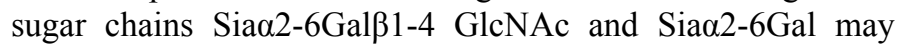
play an important role in causing the cell damage. However, it requires further investigation to determine whether Sia 2 2-6Gal $\beta 1-4$ GlcNAc is necessary for the effect or only Sia $\alpha 2-6 \mathrm{Gal}$ is sufficient.

Meanwhile, SSA and SNA had far weaker cell-damaging effect on Jurkat cells than on neurosphere cells (Figure 2) probably because the difference in the expression levels of

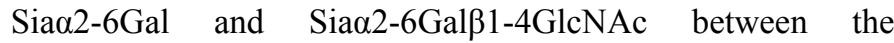
neurosphere cells and Jurkat cells. Note that it has been reported that Sian2-6Gal is restrictedly expressed on the membrane surface of ES and iPS cells and that Sian2-3Gal is expressed on differentiating cells [23]. It is, then, reasonable to assume that more Siac2-6Gal is expressed on undifferentiated neurosphere cells than differentiating Jurkat cells. Therefore, larger number of SSA and SNA bind to neurosphere cells than Jurkat cells, hence the stronger cell-damaging effect on neurosphere cells. If this idea is on the right track, it is expected that SSA and SNA have the cell-damaging effect on stem cells, such as ES cells, iPS cells and tissue stem cells.

Cytological staining with Annexin V is widely used to confirm whether cell-proliferation inhibitive cells are apoptosis. Annexin V+ cells are generally considered to be apoptosis [24]. Since the majority of neurosphere cells cultured under the presence of SSA or SNA were Annexin V+, they were considered apoptotic (Figure 3A), while none of the DNAs obtained from these cells appeared as a ladder (Figure 3B). Additionally, caspase- 3 was not active in the neurosphere cells cultured under the presence of SSA or SNA, and the activities of caspase- 8 and 9 were also significantly weak (Figure 3C). Furthermore, these cells were not rescued from apoptosis by ZVAD-FMK (Figure 3D). Generally, DNAs of apoptotic cells with active caspases (caspase-dependent apoptosis) appear as a ladder and can be rescued by Z-VAD-FMK [25]. Apoptosis of mammalian non-neural cells via Fas and Fas ligand system is regarded as a typical example of caspase-dependent apoptosis $[26,27]$. On the other hand, it has been claimed that Fas and Fas ligand system in NSCs are not involved in the apoptotic induction but in the survival and proliferation of NSCs and their differentiation into neural cells [3,28]. The results of the present study indicate that SSA and SNA lead neurosphere cells to caspase-independent apoptosis via an exogenous pathway.

So far, two intracellular signaling mechanisms are well known as causes of caspase-independent apoptosis via an exogenous pathway. One is the activities of receptor-interacting protein kinase 1 (RIPK1) with tumor necrosis factor (TNF) receptors and TNF (TNFR-TNF) system [19-21]. The other is the activities of Ras, which is oncogene product found in rat sarcoma, although the exogenous pathway involved is not obvious [29]. Additionally, it is reported that Ricin, which is classified as ribosome-inactivating protein, causes the cell damage by endocytosis [22]. However, our examination revealed that none of RIPK-1, Ras, PI3K and clathrin was involved in the induction of neurosphere cells by SSA or SNA. Thus, the intracellular signaling pathway involved in the caspase-independent apoptosis of neurosphere cells caused by SSA and SNA was not identified in this study.

Glycoproteins with the terminal sugar chain of


recognized by SSA and SNA were gp39 and gp42 with the molecular weights of $39 \mathrm{kDa}$ and $42 \mathrm{kDa}$, respectively (Figure 4). The molecular weights of these molecules differed from those of well-known molecules that cause apoptosis via an 
exogenous pathway, such as Fas (45 to $46 \mathrm{kDa}$ ), TNFR1 (55 $\mathrm{kDa})$ and TNFR-2 $(75 \mathrm{kDa})$.

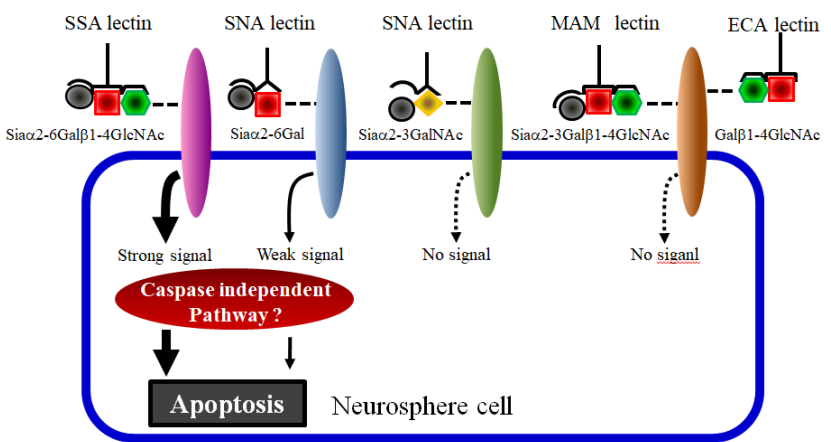

Figure 5. Schematic illustration of the study results. Caspaseindependent cell death of neurosphere cells is caused by SSA or SNA binding to N-linked glycoproteins (gp39 and gp42) with terminal

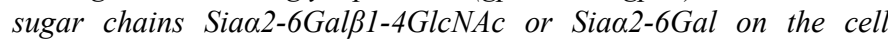
membrane. Neither RIPK-1 nor Ras is involved in the intracellular signaling which leads neurosphere cells to caspase-independent apoptosis

The results obtained in this study are summarized in Figure 5. The trigger which leads neurosphere cells to caspaseindependent apoptosis is SSA or SNA binding to gp39 and gp42. Intracellular signaling molecules that induce this caspase-independent apoptosis are still unknown. We suppose that SSA/SNA-induced caspase-independent apoptosis of neurosphere cells is involved in the cell death of undifferentiated neural cells during the development of the nervous system.

\section{Conflicts of Interest}

The authors indicate no potential conflicts of interest.

\section{Acknowledgement}

This study was partially supported by Ohu University research funding.

\section{References}

1. Reynolds BA, Weiss S. Generation of neurons and astrocytes from isolated cells of the adult mammalian nervous system. Science 1992; 255: 1707-1710.

2. Homem CCF, Repic M, Knoblich JA. Proliferation control in neural stem and progenitor cells. Nat Rev Neurosci 2015; 16: 647-659.

3. Imayoshi I, Sakamoto M, Yamaguchi M, Mori K, Kageyama R. Essential roles of Notch signaling in maintenance of neural stem cells in developing and adult brains. J Neurosci 2000; 30: 3489-3498.

4. Kotani M, Sato Y, Ueno A, Ito T, Itoh K. A novel monoclonal antibody against neuroepithelial and ependymal cells and characteristics of its positive cells in neurospheres. Cell Mol Neuobiol 2016; 36: 11-26.

5. Pfenninger CV, Steinhoff C, Hertwig F, Nuber UA. Prospective isolated CD133/CD24-positive ependymal cells from the adult spinal cord and lateral ventricle wall differ in their long-term in vitro self-renewal and in vivo gene expression. Glia 2011; 59: 68-81.

6. Rietze RI, Valcanis H, Brooker GF, Thomas T, Voss AK. Purification of pluripotent neural stem cells from the adult mouse brain. Nature 2001; 412: 736-739.

7. Uchida N, Buck DW, He D, Reitsma MJ, Masek M. Direct isolation of human central nervous system stem cells. Proc Natl Acad Sci USA 2000; 97: 14720-14725.

8. Kotani M, Okamoto S, Imada M, Itoh K, Irie A. Flow cytometric analysis of mouse neurospheres based on the expression level of RANDAM-2. Neurosci Lett 2007; 413: 25-30.

9. Kaku H, Tanaka Y, Tazaki K, Minami E, Mizuno H. Sialylated oligosaccharide-specific plant lectin from Japanese elderberry (Sambucus sieboldiana) bark tissue has a homologous structure to type II ribosome-inactivating proteins, ricin and abrin. J Biol Chem 1996; 271: 1480-1485.

10. Shibuya N, Goldstein IJ, Broekaert WF, Nsimba-Lubaki M, Peeters B. The elderberry (Sambucus rigra L.) barl lection recognizes the Neu5Ac $(\alpha 2-6)$ Gal/GalNAc sequence. J Biol Chem 1987; 262: 1596-1601.

11. Rojo MA, Yato M, Ishii-Minami N, Kaku H, Citores L. Isolation, cDNA cloning, biological properties, and carbohydrate binding specificity of sieboldin-b, a type II ribosome-inactivating protein from the bark of Japanese elderberry (Sambucus sieboldiana). Arch Biochem Biophys 1997; 340: 185-194.

12. Chen YF, Boland CR, Kraus ER, Goldstein IJ. The lectin Griffonia simplicifolia I-A4 (GS I-A4) specifically recognizes terminal alpha-linked $\mathrm{N}$-acetylgalactosaminyl groups and is cytotoxic to the human colon cancer cell lines LS174t and SW1116. Int J Cancer 1994; 57: 561-567.

13. Matsumoto N, Toyoshima S, Osawa T. Characterization of the $50 \mathrm{kDa}$ protein phosphorylated in concanavalin Astimulated mouse T cells. J Biochem 1993; 113: 630-636.

14. Meager A, Ungkitchanukit A, Nairn R, Hughes RC. Ricin resistance in baby hamster kidney cells. Nature 1975; 257: 137-139.

15. Morgan D, Russetti F, Gallo R. Selective in vitro growth of T lymphocytes from normal human bone marrows. Science 1975; 193: 1007-1008.

16. Corsini NS, Sancho-Martinez I, Laudenklos S, Glagow D, Kumar S. The death receptor CD95 activates adult neural stem cells for working memory formation and brain repair. Cell Stem Cell 2009; 5: 178-190.

17. Towbin H, Staehelin T, Gordon T. Electrophoretic transfer of proteins from polyacrylamide gels to nitrocellulose sheets: procedure and some application. Proc Natl Acad Sci USA 1979; 76: 4350-4354.

18. Ovadje P, Chatterjee S, Griffin C, Tran C, Hamm C. Selective induction of apoptosis through activation of caspase- 8 in human leukemia cells (Jurkat) by dandelion root extract. J Ethnopharmacol 2011; 133: 86-91. 
19. Degterev A, Hitomi J, Germscheid M, Ch'en IL, Korkina O. Identification of RIP1 kinase as a specific cellular target of necrostatins. Nat Chem Biol 2008; 4: 313-321.

20. Degterev A, Huang Z, Boyce M, Li Y, Japtap P. Chemical inhibitor of non-apoptotic cell death with therapeutic potential for ischemic brain injury. Nat Chem Biol 2005; 1: 112-119.

21. Holler N, Zaru R, Micheau O, Thome M, Attinger A. Fas triggers an alternative, caspase- 8 -independent cell death pathway using the kinase RIP as effector molecule. Nat Immunol 2000; 1: 489-495.

22. Lord JM, Roberts LM, Robertus JD. Ricin: structure, mode of action, and some current applications. FASEB J 1994; 8: 201-208.

23. Tateno H, Toyota M, Saito S, Onuma Y, Ito Y. Glycome diagnosis of human induced pluripotent stem cells using lectin microarray. J Biol Chem 2011; 286: 20345-20353.

24. Vermes I, Haanen C, Steffens-Nakken H, Reutelingsperger C. A novel assay for apoptosis. Flow cytometric detection of phosphatidylserine expression on early apoptotic cells using fluorescein labelled Annexin V. J Immunol Methods 1995; 184: 39-51.

25. Tanuma S, Shiokawa D, Tanimoto Y, Ikekita M, Sakagami H. Benzylideneascorbate induces apoptosis in L929 tumor cells. Biochem Biophys Res Commun 1993; 194: 29-35.
26. Kumar S, Lavin MF. The ICE family of cysteine proteases as effectors of cell death. Cell Death Differ 1996; 3: 255-267.

27. Los M, Wesselborg S, Schulze-Osthoff $K$. The role of caspases in development, immunity, and apoptotic signal transduction: lessons from knockout mice. Immunity 1999; 10: 629-639.

28. Knight JC, Scharf EL, Mao-Draayer Y. Fas activation increases neural progenitor cell survival. J Neurosci Res 2010; 88: 746-757.

29. Chi S, Kitanaka C, Noguchi K, Mochizuki T, Nagashima Y. Oncogenic Ras triggers cell suicide through the activation of a caspase-independent cell death program in human cancer cells. Oncogene 1999; 18: 2281-2290.

\section{*Correspondence to}

Masaharu Kotani

Department of Molecular and Cellular Biology

Faculty of Pharmaceutical Sciences

Ohu University

Fukusima

Japan 